Original Research Paper

\title{
A New Computer Science Student Recruitment Strategy University Of Sharjah (UOS) Case Study
}

\author{
Manar Abu Talib and Ashraf Elnagar \\ University of Sharjah, P.O. Box 27272, Sharjah, United Arab Emirates
}

Article history

Received: 17-03-2014

Revised: 11-05-2014

Accepted: 23-08-2014

Corresponding Author:

Manar Abu Talib

University of Sharjah, P.O. Box

27272, Sharjah, United Arab

Emirates

Email: manar.abutalib@gmail.com

\begin{abstract}
In this study, we focus on two objectives: (1) To raise awareness of the computing field in three groups of students-high school, freshmen in their first term of university (i.e., students taking the Introduction to IT course) and freshmen in their second term of university (i.e., students taking the Programming I course); and (2) to organize visible CS/IT activities (i.e., robots, the Google Developer Group (GDG), Hour of Code, etc.) and involve as many students as possible. We conducted a detailed survey among these three groups of students to measure the effectiveness of making presentations on CS/IT and determine whether or not awareness of computer science increased as a result. As well, we organized a series of CS/IT activities and events. We measured the effectiveness of the Hour of Code activity on 515 students from grades 1 to 5 . The survey results were promising and we conclude that such efforts should continue to be a topic of research into student enrollment growth in the future academic terms. It is also framed to benefit faculty members, administrators and others throughout the global community.
\end{abstract}

Keywords: Computer Science, Student Recruitment, University of Sharjah, High School, Introduction to IT, Programming I, NAO Robot, Google Developer Group, Hour of Code

\section{Introduction}

Based on worldwide CS enrollment data over the past three decades, the majority of academics believe that these numbers are following a cyclical pattern. Recently, reports have shown that graduate and undergraduate enrollment grew for the fifth straight year in the USA (Zweben, 2013). UAE enrollment numbers support this observation. Figure 1 depicts the number of students enrolled in the Department of Computer Science (DCS) at University of Sharjah (UoS) since its inception in 1997, this data was obtained from the Enrollment Management at UoS (EM, 2013). The spike in enrollment during the period of 1997 to 2003 was due, in large part, to the "dot-com boom", which was an international trend. During this time, there was an enormous demand for software engineers and CS graduates were highly paid. The Y2K (Year 2000) issue emerged in this time period as well, forcing organizations, both commercial and governmental, to carry out exhaustive testing of their systems and applying remedies to avert a potential crisis. The issue was over by $2000 / 2001$. At the same time, the second "dot-com crash" began, leading to an economic growth crisis, which affected student enrollment in CS. Moreover, the university was going through a major expansion phase, resulting in the addition of new colleges and several new programs. Medical programs in particular attracted a good percentage of potential CS candidates. These factors contributed to the decline in CS enrollment, beginning in 2004 and hitting a low in 2008. Students entered the field during this period purely because they liked CS. Since 2008, the decline in enrollment has reversed, for two reasons: More IT degrees are being offered and there is an increased awareness of the importance of the IT field. The students themselves are more aware of the relevance of IT tools in just about every other field of science and technology. 


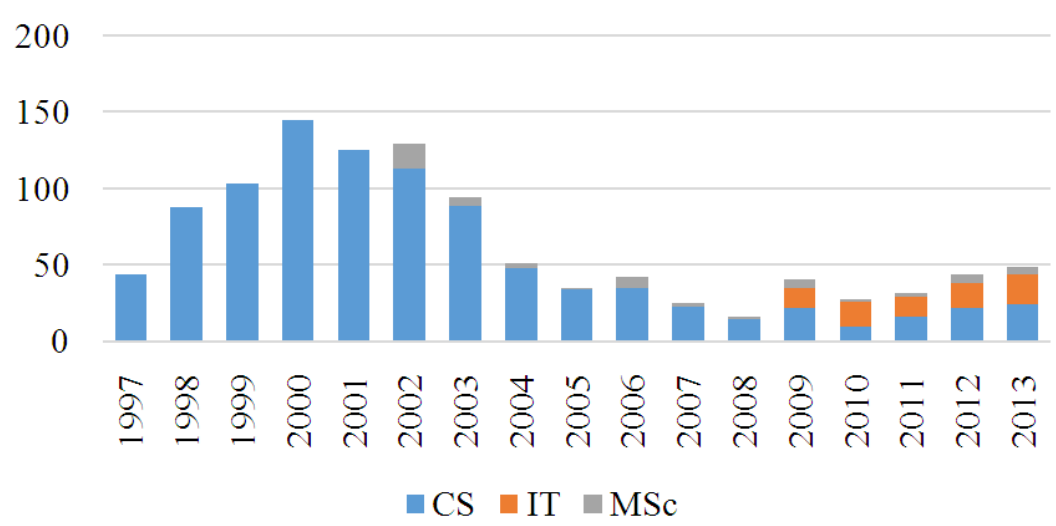

Fig. 1. Student enrollment in the department of computer science (EM, 2013)

They are also aware of the marketability of a CS degree and of the accessibility it gives them to a wide range of well-paying careers. However, we still need to strengthen recruitment efforts in order to increase enrollment in the DCS at this university.

We have noticed that a reasonable percentage of newly admitted students enroll in an academic program for reasons other than genuine interest. Some are following parental advice, while others choose a program because it is popular. For recruitment purposes, we focus here on two groups of university freshmen who were taking one of the two IT/CS courses, "Introduction to IT" or "Programming I" to benefit faculty members, administrators and others throughout the global community. Based on the large number of students and the content of both courses, we adopted a modified version of Team-Based Learning (TBL) to teach them (Elnagar and Ali, 2012; 2013).

\section{CS Student Recruitment Practices and Research}

\section{Practices and Research at a Glance}

According to (Trivette et al., 2012), there continues to be students who experience challenges bridging secondary (high school) and university education. According to (Abu Talib et al., 2012; Abu Talib and ElBarachi, 2011), the small numbers of students majoring in computing remains an issue in universities all over the world. Many approaches and strategies have been discussed and proposed, such as: Teaching computer science to children from Kindergarten to grade 12 (K-12) (CSTA, 2003); advising the advisors, who are themselves seeking to learn about the computing field and the opportunities it offers (Saunders and Hunsinger, 2008); inspiring undergraduates, through presentations and interactive activities to consider majoring in computer science and IT (Frieze and Treat, 2006;
Roberts et al., 2003); and making a special effort to attract women to majoring in this field as well. The Computer Science Teachers Association (CSTA) is a great initiative, targeting K-12 students, which is designed to increase their awareness and knowledge of computer science (CSTA, 2003). Other researchers have addressed the problem from a different point of view, by designing a format for a computing course for students not majoring in the field (Guzdial and Forte, 2005; Carter, 2006). Although there are great efforts being made to attract female students to majoring in the computing field, statistics show that the computing field remains male-dominated (Fisher et al., 1997; Force, 2008). In the United States, female enrollment in computer science and engineering has fallen from 37\% in the early 1980 s to close to $20 \%$ today. However, it seems that females comprise the majority of undergraduate students studying computer science in Arab countries, including Algeria, Egypt, Jordan, Morocco, Saudi Arabia and the UAE. UOS is no exception. Statistics show that the number of female students is double that of male students in the undergraduate and graduate programs there. In fact, the female students in the Department of Computer Science and Computer Engineering are members of two international associations: Women In Engineering (WIE); and the Arab Women In Computing Association (ArabWIC), which is an official chapter of the Anita Borg Institute for Women and Technology. However, there is still a huge need to encourage more students to major in the computing field, as UOS graduates currently take up only one-third of the available jobs in the fields of computer science, IT and software engineering.

In the Arab world, several initiatives, competitions and programs have been established that encourage students in these fields to be innovative, as well as providing them with opportunities. For example, the Arab World Association of Young Scientists 
(ArabWAYS) is the first platform created for young scientists and researchers in the Arab World to enable them to network with other scientists worldwide and with the international community (http://www.asrenorg.net). The Arab Computer Society (ACS) facilitates cooperation among computer science scholars, researchers, academics and professionals working in the Arab world, as well as with researchers worldwide who are interested in the IT industry and profession in the Arab World (http://www.arabcomputersociety.org/).

However, to the best of our knowledge, only a very few studies have addressed student enrollment in the computing field or discussed the enrollment challenges in the Arab World. In one of these (El-Sanabary, 1992) collected reports from many different countries on educational developments between 1950 and 1980 . Another included a survey of computer science education in universities in Arab countries, including Iraq, Kuwait, Qatar, Saudi Arabia and the UAE, in order to determine the stage of development of education in the major fields of computer engineering, computer science and computer-based management information systems, as recorded in 1981 (El-Sanabary, 1992). A UNESCO publication addressed science, technology and education, but did not provide a clear indication of student enrollment in the computing field in the Arab World (BouJaoude, 2003). Because of the lack of relevant articles, we have not conducted a literature review on this research topic. In this study, we hope to provide a roadmap for the Arab world to increase enrollment in the computing field.

\section{Robots, Google Developer Group (GDG) and Hour of Code}

Robots make an ideal teaching tool for classes at all levels in CS/IT education, as they offer students a hands-on experience (Barreto and Benitti, 2012; Goldman et al., 2004; Mitnik et al., 2008). We adopted this technology in the form of two NAO robots for one of the senior computer science courses at UOS. This technology helped us demonstrate teamwork, project management, problem solving and communication skills in a stimulating setting. The students were excited about using the robot to learn about computing and to implement a number of projects. They demonstrated their projects to other students and their peers at several events, bringing massive visibility to the robot, the course and, most importantly, to the department at large. The live and video-taped robotic demonstrations were attended by approximately 750 high school students, as well as 400 university freshmen. Potential candidate students (in particular those who were enrolled in the Programming I course) realized the importance of programming and their appreciation of programming increased as a result. A number of students expressed their views following the demonstrations and indicated their intention of majoring on this subject.

Students' excitement and motivation to pursue their studies increases when they realize that they could one day develop connections with international groups, as well as with well-known companies and organizations, Google Developer Groups (GDGs), for example. GDGs are for developers who are interested in Google's technologies-everything from the Android, App Engine and Google Chrome platforms, to product APIs, like Maps, YouTube and Google Calendar (https://developers.google.com/groups/). There are more than 440 GDGs in 100 countries. A GDG can take one of many forms, from just a few people getting together to watch the latest tech videos, to large gatherings offering demos and tech talks, to events like code sprints and hackathons. The Department of Computer Science at the University of Sharjah established the Sharjah GDG so that their students could be involved in GDG activities and, as a result, many highly worthwhile events were organized for them. These initiatives enhanced the visibility of this department not only at UOS, but also worldwide. Moreover, they gave the students the opportunity to learn and to develop their CS skills. One of the activities scheduled by the students was the Hour of Code, which is an annual effort initiated by Code.org to give 10 million students of all ages an opportunity to try computer science for one hour. The event takes place during the second week of December, as part of the annual Computer Science Education Week (CSEdWeek). CSEdWeek is a celebration to generate awareness of the field and to demonstrate that anyone can learn CS basics (HCPG, 2013). Our department hosted a number of students from the Australian International School (AIS) for the Hour of Code activity, in which they were challenged to monitor 515 younger students in grades 1 to 5 . This activity raised the young students' awareness of CS, while at the same time building a bridge between the schools.

\section{Research Design}

\section{CS Awareness Campaign}

At UOS, students choose their major once they have passed their final high school exams. So, in an effort to recruit more students into our computer science department, we began coordinating with the Office of Student Recruitment starting in September, 2013. We worked closely with the director and held three meetings to finalize the presentation to be made to the high school students. The presentation was created and carefully 
reviewed in consultation with $\mathrm{CS}$ faculty members. The following issues were addressed:

- What a computer science professional looks like, e.g., appearance, gender, work habits, emotional state, sociability, intelligence, income, etc

- Reasons for choosing information technology or computer science as a career

- The ubiquitous nature of computers

- Careers in computer science

- Potential employers of CS/IT graduates

- The top 10 reasons to major in computing

- Misconceptions about computer science

- Future trends: Job growth in science and technology; comparison of current supply with future demand for holders of Bachelor's and postgraduate degrees; contribution of CS/IT to overall growth in science and engineering occupations

- What our CS Department offers

- Computer science courses

- Computer science clubs

- Two videos: Our robot and our department's people

As a result of these meetings, the Student Recruitment Office team coordinated with five high schools (251 students) to give a general presentation about UOS, followed by our CS presentation.

We gave a similar presentation to the students in the Introduction to IT (350 students) and Programming I courses (64 students), both of which are prerequisites for programs in many other faculties, such as engineering and science, in this university and other universities in the world. Historically, students change their major in their first or second year of study. Therefore, giving the presentation to students in these two courses provides an excellent opportunity to raise awareness about the importance of the computing field. These students have little or no knowledge of the exciting opportunities this field can offer and providing them with more information about CS careers and the high demand for CS professionals can help to generate and encourage interest. In the next section, we show that students in their first or second year of study clearly know very little about computer science and hadn't considered it an option for their major when they applied to university. We conclude from this that a student recruitment committee should be formed within the department to address the lack of information provided to university applicants. More discussion on this issue is provided in section 5.

\section{Visible CS Events and Activities}

UOS has a large number of student clubs. The Department of Computer Science has one, which is the
Computer Science Society (CSS). It was perhaps not as visible as other clubs and so the chairman of the department asked faculty members to inject new life into it. As a result, the Sharjah GDG was established and the CSS had a new way of organizing events and engaging in international CS activities. The CSS went on to offer a number of the CS activities and events such as Google week, University Programming Contest (UPC), Java wrkshop, Microsoft seminars, ...etc.

The objective of these activities was twofold: To give CS students real-life experience and to build bridges with international organizations. Another outcome was that they empowered the students to become ambassadors, who could, in turn, deliver a positive message about the opportunities that exist for them in this department, as students have a tendency to listen to their peers when considering their choice of major. The use of robots was also a constructive device, inspiring students to ask questions and generating increased interest in the computing field. In addition, we gave several live demonstrations of the department's two NAO robots.

Finally, a total of 515 students in the Junior School at AIS took part in the Hour of Code. The schedule for all grade levels was as follows: Grade 1: 8:15-9:15 am; Grades 2/4/5: 9:30-10:30 am; and Grade 3: 11:30-12:30 pm.

\section{Results}

The findings from the survey data analysis showed more commonalities than differences in the results of making the presentations to the high school students and to the Introduction to IT students and the Programming I students. We explain the results in more detail in the subsections below.

\section{High School Presentation Results}

One matrix question was used to check more than one answer in order to show the students' thoughts about computer science before delivery of the presentation.

Most students (both male and female) knew very little about computer science prior to the presentation. The second highest rated option, selected by both male and female students, was "It's a job for a technician". This reflects the common misconception that many students have about CS, which was discussed in the presentation. The other misconception, which is that CS is a male-dominated field, is not reflected in these survey results. More students described a job in CS as difficult, rather than easy. A significant number of students realize that it is an important field of study, which is a reflection of market need. Finally, more male students than female students perceive that computer science is fun, rather than boring, whereas female students perceive it as boring. 
Forty-two male students thought that the presentation was Excellent/Very Good. They represent $62 \%$ of the total number of students. The more interesting result was that $82 \%$ of the male students agreed that they learned some new and interesting things about CS and IT majors. More than half $(62 \%)$ found that CS is interesting and needed and that it is valuable for everyone to have a CS background.

As for the female students, around 67 of them, or $78 \%$ of the total number of students, thought that the presentation was Excellent/Very Good. Ninety-one percent of them stated that they learned some new and interesting things about CS and IT majors. However, half of them $(46.5 \%)$ think that CS is interesting and needed and that it is valuable for everyone to have a CS background. The other half $(51.16 \%)$ think that CS is needed, but are not interested in acquiring CS knowledge.

The presentation was designed to be more of an interactive activity than a lecture and overall, both male and female students participated actively in it. Ideas were shared and questions asked. The female students were more interested in talking to us after the presentation and asked more questions generally. Some of the comments they made in the survey were the following: "I am now interested in (the) computing field even more"; "Great presentation"; "Very nice and entertaining presentation"; "Sadly, that is not my choice"; and, "So funny, I laughed!".

\section{Introduction to IT and Programming I Presentation Results}

A survey was handed out to the students enrolled in the Introduction to IT course prior to delivery of the presentation. The following points were addressed in the survey: (1) Whether or not the students were $100 \%$ decided on their major; (2) the most important factors affecting their decision when choosing a major; (3) how the students felt about a CS/IT major; and (4) their fears/interests in a CS/IT major.

Two hundred and eight students agreed to participate in this survey-58\% were in their first year of study, 22\% in their second year, $12 \%$ in their third year and $8 \%$ in their fourth year. We learned from these figures that the $58 \%$ of students in their first year of study might be uncertain about their major and could be targeted for CS/IT recruitment. However, in the second question of the survey, $61 \%$ of students answered that they were $100 \%$ decided on their major, indicating that we can target only $39 \%$ of them for CS/IT recruitment. In the survey we asked them about the factors that affected their decision making while applying to UOS. Obviously, most students are aware that they chose their major based on their interests and strengths. This is positive, but we still believe that some students might be unaware of a hidden interest in the computing field and of their potential to succeed in that field, owing to a lack of information. Moreover, because family is also very important in influencing a student's choices $(67 \%)$, it is therefore critical to raise their parents' level of knowledge and awareness of computer science.

The students' opinions of computer science were more varied before the presentation than after it $(35 \%$ of students don't know much about CS). Again, one matrix question was used to check more than one answer. Overall, these results were similar to those obtained from the high school students; however, these students had a greater awareness of CS/IT, because of the knowledge they had gained from the Introduction to IT course (48\% of students agree that it is important field).

We received 208 answers from students in the Introduction to IT course, in which they define their interest in CS and in IT majors, as well as their fears about technology. We provide the answers most often given by the respondents: "I think it's very important, but it doesn't suit my interest"; "actually, it interested and important but it is hard major"; "I think this major promises for high jobs in the future"; "I don't really like it and I don't know a lot about it"; "I don't know a lot about the major but I have fun during my IT class and in high school we've studied VB program"; "it involves some complicated mathematics and I'm bad at math". Note that we have reproduced their comments here as they wrote them, without correction or editing, in order to reflect their true feelings about the CS presentation.

After the delivery of the CS presentation to students in both courses, one hundred and sixty-one students in the Introduction to IT course thought that the presentation was Excellent/Very Good. This number represents $80 \%$ of the total number of students. In addition, $90 \%$ of the students agreed that they learned some new and interesting things about CS and IT majors. A high percentage (72\%) think that computer science is interesting and needed and that it is valuable for everyone to have a CS background.

As for the students in the "Programming I" course, they all thought that the presentation was Excellent/Very Good. Moreover, all of them agreed that they learned some new and interesting things about CS and IT majors. A high (90\%) think that computer science is interesting and needed and that it is valuable for everyone to have a CS background.

The students in both courses were strongly attracted to the live demos of the NAO robots, the Google Developer Group, the videos and the Arab Women in Computing Association.

We also received very interesting feedback from the students in both courses (around 201 replies).

\section{Hour of Code Results}

The Hour of Code activity was an excellent experience. Most of the students who enjoyed the Angry Birds activity were from grades 4 and 5. This activity 
enabled the students to learn about moving forwards and backwards, turning left and right, making loops and responding to 'if' conditions. The chairman of the Department of Computer Science commented: "Being part of the Hour of Code gave them a chance to participate on a technological platform with millions of other students around the world, as well as a taste of computer science and the limitless possibilities it could offer. The activity opened the way for children to acquire certain skill sets and to get a taste of how things work, with the technologies they use in their day-to-day lives. It was wonderful to see the students so engaged in the activities, from the younger students to the older ones, their eyes shone with excitement as they worked their way through the levels. We can't wait to participate again next year!"

One hundred and twelve students from grades 4 and 5 participated in a survey before playing the Angry Birds game. Sixty-nine percent of them believe that CS is a field of study available to females and males, $62 \%$ think that CS professionals are connected to the world, $53 \%$ believe that CS professionals are smart and $45 \%$ think that these professionals are making a great deal of money.

One hundred and twenty-three students from grades 4 and 5 participated in the survey after playing the Angry Birds game. Overall, these results were interesting. The students were all able to understand the concepts "move forwards", "move backwards", "turn left," and "turn right". Ninety-one percent of them understood the concept "repeat...times...do" and 53\% of them understood the concept of "if path...do". However, 23\% of them answered that they weren't sure that they understood the concept of "if path...do". For the last level of the game, which was about the concept of "if path...do else", $25 \%$ understood and $31 \%$ were not sure. Finally, $89 \%$ of the students think that computer science is fun and $49 \%$ of them think it is an easy subject to learn. Thirty-one percent think that it is difficult and $20 \%$ were not sure. Most teachers commented as follows:

"I found the activity challenging and had to concentrate to complete the task. It was wonderful to see the children so engaged in the activity. For some it was more challenging than others. A wonderful program that suited all learning skills. The children applied themselves well."

"Most of my students found the Hour of Code extremely engaging. Some still referred to it as a 'game', but all my students were shocked to discover the technology we have today."

We received different feedback from the grade 1 teachers. One of them commented:

"Having to enter the URL code for all my students was annoying. Many of my students became frustrated or 'bored'. This may be because a lot of them are ESL students and the game may have been a bit beyond them. I completed the rest of the mazes on an interactive whiteboard, which seemed to interest some of them more."

\section{Discussion}

The data analysis shows that most of the high school, Introduction to IT and Programming I students have little knowledge of the computing field, possible CS/IT careers, of the needs of the market. This may lead them to dismiss CS as an option for their academic major. After delivering the CS presentation to these three groups, the students expressed a great deal of satisfaction about the presentation content and most of them indicated that they had learned something new about the computing field. A high percentage think it is an important field and that they should have a CS background. However, one presentation is not enough to increase enrollment in the long term. For this reason, in December 2013, a request was submitted to the chairman of the Department of Computer Science for a Student Recruitment Committee to achieve the following goals:

- Increase the department's visibility and generate interest in the CS field among high school students and among university students interested in changing their major

- Maintain continuous promotional efforts to boost student enrollment in CS as a major

- Develop and deploy a structured framework for department-wide activities to promote CS

We began by creating a student recruitment strategy for our department, which was adopted and modified from a previous context (Abu Talib et al., 2012; Abu Talib and El-Barachi, 2011). That iterative student recruitment strategy consists of two categories of activities:

- Targeted one-on-one presentations involving close interactions with young high school students, as a means to increase their awareness about the CS field and the Department of CS offerings

- University-wide events targeting the whole UOS student body, as a means to represent and increase the department's visibility

NAO robots, the Sharjah Google Developer Group and the Hour of Code activity were great examples of student engagement and resulted in a positive image for the Department of Computer Science, both inside and outside the UOS community. The Sharjah Google Developer Group, for example, attracted a large number of student participants from inside and outside the Department of Computer Science and others put their names on a mailing list to be notified of GDG events and activities. Also, Sharjah TV interviewed a CS faculty 
member and his students about their projects with the NAO robots. Finally, based on these CS activities and events, articles about the Department of Computer Science were published by the media center at UOS.

To that end, this new CS student recruitment strategy can be applied in any CS/IT department in any university and produce the same positive impact for three reasons:

- The three groups of students targeted in this study are the fundamental and key groups that CS/IT departments may consider for increasing the enrollment

- Introduction to IT and Programming I are internationally core courses and prerequisites for other courses for other colleges

- NAO robots, the Google Developer Group and the Hour of Code activity are international initiatives and can be applied in any university in the world

\section{Student Recruitment Committee Recommendations for Fall 2014}

Our presentations were essential to accomplishing our mission of raising awareness of the computer science field, as discussed in section 4 . The students showed a great deal of interest in what they had learned and reported that their ideas of the computing field had changed in a positive way as a result. While we can say that the presentations reduced, if not eliminated, previous misconceptions about the computing field, there are a few recommendations to be considered for next term:

- Combine the Introduction to IT sections, so that the presentation is delivered once, or a maximum of twice. Do the same for Programming I. It was quite tiring to make the presentations to several sections in the fall of 2013

- Create a different presentation for the Programming I sections, focusing specifically on the importance of programming and its careers

- Target students who are taking English courses. This needs coordination with the English Center; for example, students could be given an English language proficiency test to evaluate their suitability to pursue a CS career

- Work on improving the teaching materials for both the Introduction to IT and Programming I courses. This would need the cooperation of the course coordinators

- Organize a CS Day and invite high school students and their families to attend. This event would involve presentations, booths, alumni speakers and live demos. Families are one of the main influences on the students' choice of a major and it would be a good idea for CS faculty members to have the opportunity to address parents face-to-face, to respond to their questions and concerns
- Work on the promotional materials, such as CS brochures, CS bulletin boards, CS website, CS social media, roll up banners, etc

- Establish a robotics club, as most of the students found them very inspiring

\section{Conclusion}

This research paper proposed a new student recruitment strategy to increase the enrollment in computer science and IT fields. The promising results achieved in this study suggest that future research should include these four major research topics: (1) Student enrollment growth and the impact on enrollment of applying the proposed recruitment strategy; (2) a survey on the new presentation that will be made to students taking programming courses and to students taking English courses; (3) a survey of families attending CS Day; and (4) a survey on senior CS students and on CS alumni.

\section{Acknowledgement}

The researchers thank Professor Mahir Ali, Chairman of the Department of Computer Science, for his support of this research. We are also grateful to the Office of Student Recruitment at UOS, the coordinators of the Introduction to IT and Programming I courses, the Australian International School and the Google Developer Group.

\section{References}

Abu Talib, M. and M. El-Barachi, 2011. Revitalizing the IT college: A case study. Proceedings of the 2nd Manipal Conference on Technology Management (CTM' 11), Manipal University, Dubai, pp: 1-5.

Abu Talib, M., M. El-Barachi and O. Ormandjieva, 2012. An innovative marketing strategy to promote our college of IT: Zayed University case study. Issues Inform. Sci. Inform. Technol., 9: 161-175.

Barreto, F. and V. Benitti, 2012. Exploring the educational potential of robotics in schools: A systematic review. Comput. Edu., 58: 978-988. DOI: 10.1016/j.compedu.2011.10.006

BouJaoude, S., 2003. Science and technology education in the arab world in the 21 st Century. Int. Sci. Technol. Environ., 28: 1-1.

Carter, L., 2006. Why students with an apparent aptitude for computer science don't choose to major in computer science. Proceedings of the 37th SIGCSE Technical Symposium on Computer Science Education, Mar. 01-05, Houston, TX, USA, pp: 27-31. DOI: $10.1145 / 1121341.1121352$

CSTA, 2003. A model curriculum for K-12 computer science: Final report of the ACM K-12 task force. USA, ACM. 
Elnagar, A. and M. Ali, 2012. A modified team-based learning methodology for effective delivery of an introductory programming course. Proceedings of the 13th Annual Conference on Information Technology Education, Oct. 11-13, Calgary, AB, Canada, pp: 177-182. DOI: $10.1145 / 2380552.2380604$

Elnagar, A. and M.S. Ali, 2013. Survey of student perceptions of a modified team based learning approach on an information technology course. Proceedings of the Palestinian International Conference on Information and Communication Technology, Apr. 15-16, IEEE Xplore Press, Gaza, pp: 22-27. DOI: 10.1109/PICICT.2013.14

El-Sanabary, N., 1992. Education in the Arab Gulf States and the Arab World: An Annotated Bibliographic Guide. 1st End., Taylor and Francis, ISBN-10: 0824082494, pp: 572.

EM, 2013. Enrollment management. University of Sharjah.

Fisher, A., J. Margolis and F. Miller, 1997. Undergraduate women in computer science: Experience, motivation and culture. Proceedings of the 28th SIGCSE Technical Symposium on Computer Science Education, Feb. 27-Mar. 01, San Jose, CA, USA, pp: 106-110. DOI: $10.1145 / 268084.268127$

Force, I.D., 2008. IST strategic plan: Building the brand through partnership networks for excellence. University Park.

Frieze, C. and E. Treat, 2006. Diversifying the images of computer science: Carnegie mellon students take on the challenge! USA. Proceedings of Women in Engineering Programs and Advocates Network (WEPAN) Conference.
Goldman, R., A. Eguchi and E. Sklar, 2004. Using educational robotics to engage inner-city students with technology. Proceedings of the 6th International Conference on Learning Sciences, (CLS' 04), pp: 214-221.

Guzdial, M. and A. Forte, 2005. Design process for a non-majors computing course. Proceedings of the 36th SIGCSE Technical Symposium on Computer Science Education, Feb. 23-27, St. Louis, MO, USA, pp: 361-365. DOI: 10.1145/1047344.1047468

HCPG, 2013. Computer Science Education Week. HCPG.

Mitnik, R., M. Nussbaum and A. Soto, 2008. An autonomous educational mobile robot mediator. Autonomous Robots, 25: 367-382. DOI: $10.1007 / \mathrm{s} 10514-008-9101-\mathrm{z}$

Roberts, E.S., M. Kassianidou and L. Irani, 2003. Encouraging women in computer science. Stanford, CA.

Saunders, M.L. and D.S. Hunsinger, 2008. Encouraging students to choose a computer-related major: The influence of guidance counselors. Inform. Syst. Edu. J., 6: 419-428.

Trivette, C.M., J. Wilson-Kearse, C.J. Dunst and D.W. Hamby, 2012. Access to higher education among high school students: Challenges and solutions. J. Soc. Sci., 8: 252-257. DOI: 10.3844 /jssp.2012.252.257

Zweben, S., 2013. Computing degree and enrollment trends. Comput. Res. Assoc. 